\title{
REVIEW
}

\section{Viruses, gene therapy and stem cells for the treatment of human glioma}

\author{
AP Kyritsis ${ }^{1,2}$, C Sioka ${ }^{2}$ and JS Rao ${ }^{3}$ \\ ${ }^{1}$ Department of Neurology, University Hospital of Ioannina, Ioannina, Greece; ${ }^{2}$ Neurosurgical Research \\ Institute, University of Ioannina, Ioannina, Greece and ${ }^{3}$ Department of Cancer Biology and Pharmacology, \\ University of Illinois College of Medicine at Peoria, Peoria, Illinois, USA
}

Cancer gene therapy is based on the transfer of genetic material to cancer cells to modify a normal or abnormal cellular function, or to induce cell death. Modified viruses or stem cells have been used as carriers to transfer the genetic material to cancer cells avoiding trafficking through normal cells. However, although the current vectors have been successful in delivering genes in vitro and in vivo, little has been achieved with human cerebral gliomas. Poor transduction efficiency of viruses in human glioma cells and limited spread and distribution to the tumor limits our current expectations for successful gene therapy of central nervous system cancer until and if effective transfer vehicles are available. Nevertheless, continuing research in better vector development may overcome these limitations and offer a therapeutic advantage over the standard therapies for glioma.

Cancer Gene Therapy (2009) 16, 741-752; doi:10.1038/cgt.2009.52; published online 31 July 2009

Keywords: adenovirus; retrovirus; oncolytic virus; stem cells

\section{Introduction}

Glioma is a devastating disease with short survival and poor response to chemotherapeutic drug intervention. The reasons for the poor efficacy of these agents include the blood-brain barrier, which forms a pharmacological sanctuary, the heterogeneity of glioma and selection of chemotherapy-resistant clones and its low immunogenicity. ${ }^{1}$ It is clear that new therapeutic strategies are needed for treatment of this devastating tumor. ${ }^{2,3}$ Glioma is a disease of multiple genes. Thus, theoretically, they could be treated by targeting their fundamental molecular defects. $^{4}$ The aim of gene therapy in general is to reestablish an abnormal cellular function through transfer of genetic material to cells. The ability to transfer exogenous genes to cancer cells through viral vectors has yielded a wealth of information with regard to the neoplastic processes that occur at molecular and cellular levels. The replacement of defective tumor suppressor genes such as p53, p16, Rb and PTEN/MMAC1 has greatly enhanced our understanding of the molecular mechanisms of cancer and has contributed to diagnosis, prognosis and therapy. ${ }^{5}$ The transfer of apoptosisinducing genes to tumors is one promising strategy for cancer gene therapy. In vitro and in vivo (nude mice)

Correspondence: Professor AP Kyritsis, Department of Neurology, University of Ioannina School of Medicine, University Campus, Ioannina 45110, Greece.

E-mail: thkyrits@uoi.gr

Received 12 January 2009; revised 16 May 2009; accepted 7 July 2009; published online 31 July 2009 transfer of exogenous E2F-1 protein by an adenovirus vector precipitated generalized apoptosis in gliomas. ${ }^{6}$ As noted earlier, a number of key technical issues needed to be successfully addressed such as efficient gene delivery and cell transplantation techniques before the application of gene therapy in the clinic. ${ }^{7}$ One of the major obstacles in transferring gene therapy from the laboratory to the patient is that an acceptable vector system has not yet been created. The ideal vector would be administered systemically transducing most of the affected cells sparing the normal tissue. ${ }^{8}$ Other significant obstacles are immune reactions against the vectors and transgenes, which may limit their repeated administration, and inappropriate insertion of vectors and transgenes that can cause host DNA mutations or deletions leading to malignant transformation. Such an example consists of the development of hepatocellular carcinoma in mice after administration of an adeno-associated virus expressing b-glucuronidase, raising concerns over the clinical use of such vectors. ${ }^{9}$ Moreover, results in animal models are often unreliable, because viruses that may be effective in animals may be ineffective in humans and the opposite. In this review, we will outline the new therapeutic strategies that may offer an advantage to currently employed standard therapies for glioma in the future.

\section{Non-proliferating viruses}

Genes encoding proteins that control cell cycle progression and apoptosis are frequently altered in gliomas. ${ }^{10}$ 
Table 1 Representative current gene therapy and virotherapy methods

\begin{tabular}{|c|c|c|c|c|}
\hline Delivery vehicle & Virus type & Mode of action & Advantages & Disadvantages \\
\hline $\begin{array}{l}\text { Non replicating } \\
\text { virus }\end{array}$ & $\begin{array}{l}\text { Adenovirus } \\
\text { Retrovirus } \\
\text { Adeno-associated virus }\end{array}$ & $\begin{array}{l}\text { Cell cycle arrest } \\
\text { Apoptosis }\end{array}$ & $\begin{array}{l}\text { Focused action depending on the } \\
\text { transferred gene }\end{array}$ & $\begin{array}{l}\text { Minimal transduction } \\
\text { efficiency } \\
\text { Intracranial administration }\end{array}$ \\
\hline $\begin{array}{l}\text { Replicating } \\
\text { viruses } \\
\text { (virotherapy) }\end{array}$ & $\begin{array}{l}\text { Modified Adenovirus } \\
\text { Modified Herpes } \\
\text { simplex virus }\end{array}$ & $\begin{array}{l}\text { Direct cell lysis by the virus } \\
\text { Transfer of genes that } \\
\text { cause cell cycle arrest or } \\
\text { apoptosis }\end{array}$ & $\begin{array}{l}\text { Multiply and spread to adjacent } \\
\text { cells } \\
\text { Restrict viral replication only to } \\
\text { tumor cells and spare normal cells }\end{array}$ & $\begin{array}{l}\text { Intracranial administration } \\
\text { Neutralizing antibodies }\end{array}$ \\
\hline Stem cells & $\begin{array}{l}\text { Can be infected with } \\
\text { viruses carrying genes } \\
\text { of interest }\end{array}$ & $\begin{array}{l}\text { Migratory tropism for } \\
\text { malignant cells }\end{array}$ & $\begin{array}{l}\text { Derived from bone marrow, skin, } \\
\text { brain Minimal accumulation to } \\
\text { normal tissues } \\
\text { Potential systemic administration }\end{array}$ & $\begin{array}{l}\text { Malignant transformation } \\
\text { potential }\end{array}$ \\
\hline
\end{tabular}

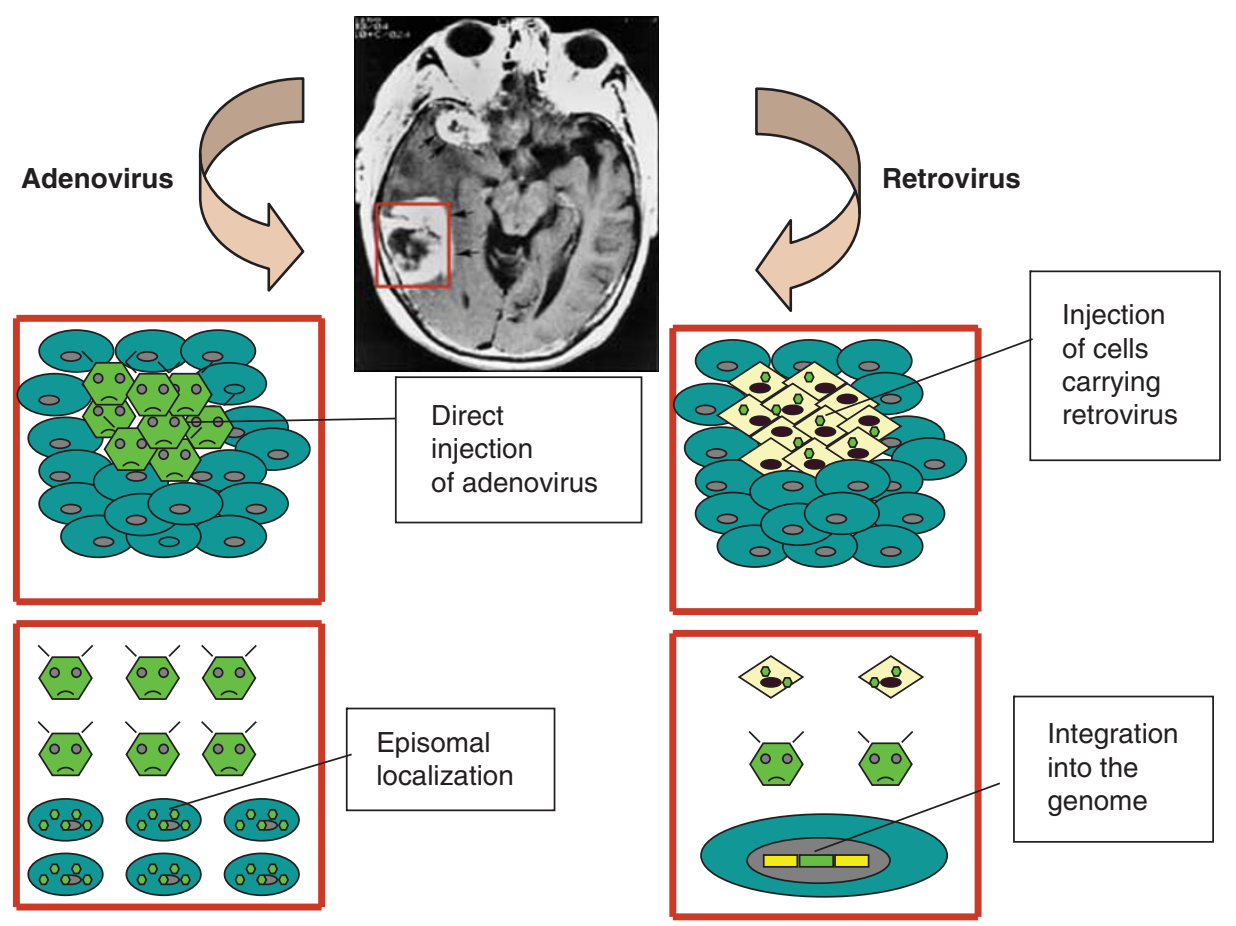

Figure 1 Examples of retrovirus-mediated or non-replicating adenovirus-mediated gene transfer to cancer cells. In the retrovirus-mediated gene transfer, a brain tumor (box) is injected stereotactically with transporter cells that contain the retroviral construct carrying a gene that needs to be expressed into the tumor cells. Upon injection into the tumor, the transporter cells release the retrovirus, which is inserted into the cellular genome resulting in long expression of the gene of interest. Such an uncontrolled insertion can sometimes result in insertional mutations. In the case of the non-replicating adenovirus-mediated gene transfer, direct injection of the concentrated viral particles carrying the gene of interest result in episomal localization of the virus and transient expression of the transferred gene.

Thus theoretically, replacement of abnormal genes with their wild-type counterparts could adjust cell cycle function and inhibit uncontrolled proliferation of tumor cells (Table 1). The transfer of normal genes to gliomas could be attained using retroviruses or adenoviruses as delivery vehicles (Figure 1). Cells synchronized in the G1-S phase are highly radiosensitive. In vitro G1 cell cycle arrest induced by adenovirus-mediated p16 gene transfer showed enhanced radiation-induced cell killing by a possibly non-apoptotic mechanism, ${ }^{11}$ and restoration of the wild-type p16 activity into p16-null SNB19 glioma cells significantly inhibited tumor-cell invasion. ${ }^{12}$
Similarly, downregulation of integrin $\alpha(v) \beta$ (3) expression and integrin-mediated signaling in glioma cells by adenovirus-mediated transfer of antisense urokinase-type plasminogen activator receptor and sense p16 genes resulted in decreased integrin-mediated biological effects, including adhesion, migration, proliferation and survival, supporting the therapeutic potential of simultaneously targeting urokinase-type plasminogen activator receptor and p16 in gliomas. ${ }^{13,14}$

However, G1 cell arrest induced by p16 gene transfer in glioma cells resulted in chemoresistance to some cytocidal drugs such as cisplatin or ACNU that require 
cycling cells to be effective. ${ }^{15}$ Similar results were noted with paclitaxel and topotecan. ${ }^{16}$ Employment of replication-deficient adenoviruses to transfer exogenous p53 and p21 into glioma cells induced apoptosis in p53 mutant cells, but overexpression of p21 had an opposite effect and induced resistance to treatments that induce apoptosis. ${ }^{17}$

Vectors derived from serotype 5 adenoviruses (Ad5) provide inefficient infection of glioma cells because of limited cell surface expression of the primary adenovirus receptor (Coxsackie-adenovirus receptor) on tumor cells. To overcome this limitation, Ad5 has been modified by genetic replacement of either the entire fiber or fiber knob domain with its structural counterpart from other Ad serotypes that recognized cellular receptors other than Coxsackie-adenovirus receptor with enhanced Ad infectivity. ${ }^{18}$ Thus, use of a capsid-modified adenoviral vector, in combination with tumor necrosis factor-related apoptosis-inducing ligand (TRAIL) expression, increased the infectivity and cell death of glioma cells compared with unmodified virus. ${ }^{19}$ Adenoviral vectors encoding either the extracellular domain of vascular endothelial growth factor receptor-2-Fc fusion protein (Ad-VEGFR2-Fc) alone, soluble endostatin alone or a combination of both were injected in mice bearing U87 intracranial gliomas. The results suggested that systemic delivery and sustained production of endostatin and soluble VEGFR2 could slow by $60-70 \%$ intracranial glial tumor growth by both reducing cell proliferation and increasing tumor apoptosis. $^{20}$ In contrast to first-generation Ad-TK, second generation high-capacity adenovirus vectors carrying the TK gene induced tumor regression and long-term survival in an intracranial glioma model, even in the presence of systemic antiadenovirus immunity, as could be encountered in patients. ${ }^{21}$ Experimental results have demonstrated that marked tumor regression occurred even though a small fraction of cells were infected by the exogenous gene. The cytotoxic effect of infected on noninfected cells is termed the bystander effect. ${ }^{22}$ Ad35, a chimeric vector was found to have lower antigenic properties, but increased ability to transfer a gene to primary glioma cells compared with Ad5 depicting it as an interesting candidate vector for gene therapy of malignant glioma. ${ }^{23}$

However, although genetic strategies to circumvent Coxsackie-adenovirus receptor deficiency in glioma cells could reproducibly expand the cellular entry mechanisms of Ad vectors in cultured and primary glioma cells, these approaches were insufficient to confer in vivo significant infectivity enhancement over unmodified Ad vectors, suggesting that other factors, such as extracellular matrix, stromal cells and the three-dimensional tumor architecture, have important roles in vivo and interfere with Ad-based gene delivery into gliomas. ${ }^{24}$ Invasive tumors, including gliomas, utilize proteinases to degrade extracellular matrix components and diffuse into the adjacent tissues or migrate toward distant ones. In addition, proteinase activity is required for the formation of new blood vessels within the tumor. Levels of the proteinase matrix metalloproteinase-2 are highly increased in gliomas. Downregulation of matrix metalloproteinase-2 through adenovirus-mediated siRNA in gliomas impaired invasion, decreased angiogenesis, induced apoptotic cell death in vitro and suppressed tumor growth of preestablished U-251 intracranial xenografts in nude mice. Thus, specific targeting of matrix metalloproteinase-2 may provide an approach for the treatment of gliomas. ${ }^{25}$

Abnormalities of the retinoblastoma tumor suppressor gene are found in the majority of cancers, including at least $30 \%$ of malignant gliomas. Earlier studies have suggested that restoration of the wild-type $\mathrm{Rb}$ protein in $\mathrm{Rb}$-null cells using an Ad5CMV-Rb results in G1 cell cycle arrest, growth suppression and inability of cells to form tumors in nude mice, indicating that restoration of wild-type retinoblastoma activity may have therapeutic utility. ${ }^{26}$ It has been suggested that the targeted expression of tumor suppressor genes such as gas1 (growth arrestspecific 1) and p53 through adenoviral vectors may provide an interesting approach for adjuvant selective glioma gene therapy. ${ }^{27}$

Several mutant herpes simplex viruses (HSVs) were reported to be cytotoxic for human glioma cells in vitro and in vivo but normal human astrocytes were two to three times less susceptible. ${ }^{28}$ The replication-defective herpes simplex virus type 1 vectors for gene transfer include vectors that were defective for the immediate early (IE) genes ICP4, ICP27 and ICP22, but expressed the IE gene ICP0, which can arrest tumor-cell division, and an IE thymidine kinase $(\alpha$-tk) gene construct that mediates suicide gene therapy in the presence of ganciclovir. Among these vectors, the recombinant vector NUREL-C2, which expressed both TNF- $\alpha$ and Cx43 along with ICP 0 and $\alpha$-tk was reported to be an attractive candidate for Phase I gene therapy safety studies in patients with recurrent malignant glioblastoma. ${ }^{29}$

\section{Oncolytic viruses}

As the replication-deficient viruses showed limited transduction efficiency, replication-competent viruses were developed to maximize the transduction efficiency (Table 1). Viral oncolysis, or virotherapy, involves the use of viruses as therapeutic agents to provoke host cell killing through multiplication and spread to adjacent cells. Oncolytic adenoviruses, also called conditionally replicative adenoviruses, can be genetically modified to restrict viral replication only to tumor cells and spare normal adjacent cells. Viral-mediated tumor destruction is propagated through infection of nearby tumor cells, and during each viral cycle, the number of viruses available for infection is multiplied. Designing and production of replication-selective tumor-specific viruses represents a novel approach for the treatment of cancer. ONYX-015 (d11520) was the prototype for oncolytic adenoviral therapy. The strategy underlying its tumor-selective cell killing was based on deletion of the viral E1B-55 kDa gene, which is crucial for efficient viral replication in normal cells, but dispensable in tumor cells. ${ }^{30}$ Another CRAd is the Delta-24 adenovirus that was developed in our laboratory in the late 1990s (Figure 2). Delta-24, 
carrying a 24-bp deletion in the E1A region responsible for binding $\mathrm{Rb}$ protein, could replicate and kill cancer cells, but not normal cells or cancer cells with functional $\mathrm{Rb}$ pathway. ${ }^{31}$ Comparison of antiglioma activity in vitro and in vivo between Delta-24 and RA55, an E1B-55 kDa mutant adenovirus showed that Delta-24 induced a more potent antiglioma effect in vitro than RA55, indicating that E1A mutant adenoviruses targeting the $\mathrm{Rb}$ pathway are more powerful putative agents than E1B mutant adenoviruses. $^{32}$

The paucity of Coxsackie adenovirus receptors on tumor cells led to the construction of the Delta-24-RGD, that has an RGD-4C peptide motif inserted into the adenoviral fiber, which allows the adenovirus to anchor directly to integrins. ${ }^{33}$ Delta-24-RGD administered in four glioblastoma stem cell lines and xenografts derived from glioma stem cells showed induction of tumor cell death by autophagy both in vitro and in vivo. ${ }^{34}$ ICOVIR-5 adenovirus encompasses an early 1A adenoviral (E1A)

a

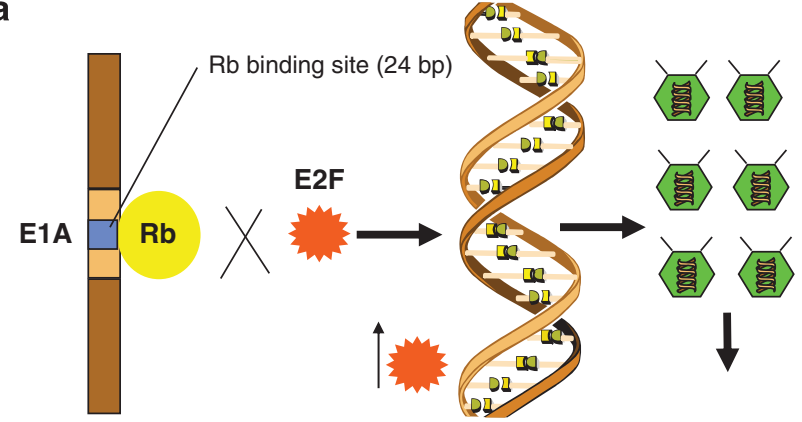

WT adenovirus

Infected cell DNA (normal or malignant)

b
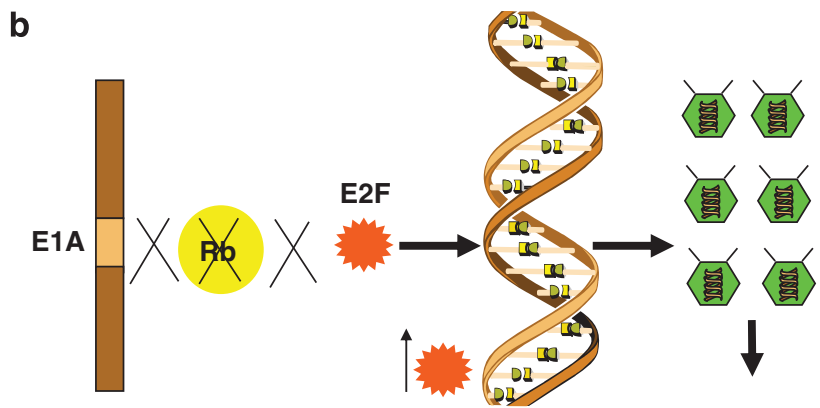

D24 adenovirus

Infected cancer cell DNA Cell lysis

C
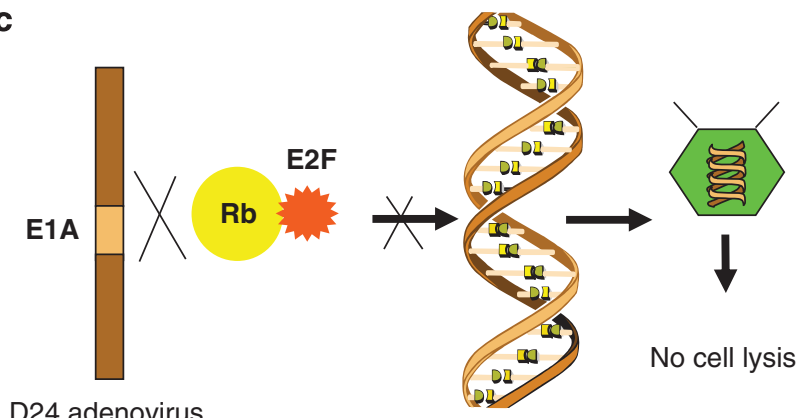

D24 adenovirus

Infected normal cell DNA

deletion in the retinoblastoma $(\mathrm{Rb})$ protein-binding region, substitution of the E1A promoter for E2Fresponsive elements and an RGD-4C peptide motif inserted into the adenoviral fiber to enhance adenoviral tropism. This virus was reported to show occupancy of the ectopic adenoviral E2F1-responsive elements by the endogenous E2F1 protein resulting in high level of E1A expression in cancer cells and potent antiglioma effect. ${ }^{35}$ A conditionally replication-competent Ad5-based vector with the Ad35 fiber shaft and knob domains (Ad5/35) had a potent antiglioma effect suggesting that Ad35-based vectors may be useful for the treatment of glioma. ${ }^{36} \mathrm{~A}$ replication-selective adenovirus (CB1) having a double deletion of the $24 \mathrm{bp} \mathrm{Rb}$-binding region in the Ela gene, and a $903 \mathrm{bp}$ deleted region in the E1b gene that abrogates the expression of the p53-binding E1B-55 $\mathrm{kDa}$ protein, exerted a potent anticancer effect in vitro in U-251 MG, U-373 MG and D-54 MG human glioma cell lines. In vivo experiments using intracranially implanted D-54MG glioma xenografts improved survival of nude mice. ${ }^{37}$

Oncolytic HSVs that have been tested in clinical trials have had mutations in HSV $\gamma-34.5$ and/or ICP 6 genes. Deletion of the $\gamma-34.5$ gene that has a role in viral virulence causes the HSV-1 virus to be non-virulent in neuronal cells. ${ }^{38}$ The ICP 6 gene encodes a viral ribonucleotide reductase that allows HSV replication in quiescent cells, but it is not required for virus growth and DNA synthesis in dividing cells. ${ }^{39}$ Thus, the differential effect of the ICP-6 gene in quiescent versus cycling cells provided the rational for use of ICP-6 mutated HSVs in clinical trials with oncolytic virotherapy. The fact that glioma tumors though show only a small percentage of

Figure 2 Simplified mechanism of function of the Delta 24 adenovirus. (a) Effect of the wild-type adenovirus after infection of cells (normal or malignant). The E1A proteins are the first virusspecific polypeptides synthesized after adenoviral infection and are required for viral replication to occur. Binding of the viral E1A proteins to the intact cellular retinoblastoma $(\mathrm{Rb})$ protein, results in release of $\mathrm{E} 2 \mathrm{~F}$ from preexisting cellular E2F-Rb complexes. The E2F is then free to activate both the $E 2$ promoter of the adenovirus and several cell cycle-regulatory genes. The transcriptional activation of these cellular genes in turn helps to create an environment suitable for viral DNA synthesis in otherwise quiescent cells, leading to viral replication and cell lysis. (b) Effect of the Delta-24 adenovirus in cancer cells with defective Rb pathway. Two segments of E1A are important for binding Rb; one includes amino acids 30-60 (CR1) and the other includes amino acids 120-127 (CR2). Delta-24 adenovirus was constructed by deletion of CR2 and shown to prevent the formation of detectable $\mathrm{E} 1 \mathrm{~A} / \mathrm{Rb}$ complexes in vitro or in vivo. Although Delta24 adenovirus has an E1A protein that cannot bind $\mathrm{Rb}$, cancer cells with defective $\mathrm{Rb}$ pathway have already inactivated $\mathrm{Rb}$, which allows unbound E2F activity to commence adenoviral transcription, replication and cell lysis. (c) Effect of the Delta-24 adenovirus in normal cells with intact $R b$ pathway. In normal cells with intact $\mathrm{Rb}$ function, Delta24 adenovirus has an E1A protein that cannot bind $\mathrm{Rb}$, which remains associated with $\mathrm{E} 2 \mathrm{~F}$ resulting in no adenoviral transcription, replication or cell lysis. Thus, a functional retinoblastoma pathway will typically protect a cell from adenoviralmediated cell death. 
cycling cells would render this treatment ineffective. However, a recent report indicated that an HSV with defective ICP-6 function could replicate in quiescent murine embryonic fibroblasts if they had homozygous p16 deletions. As most of the gliomas have a defective p16/Rb pathway, these findings could indicate a specific tumor-targeted effect of the mutated oncolytic HSV even if the cells are not cycling. ${ }^{40}$ Histone deacetylase inhibitors such as valproic acid, are a new class of antineoplastic agents because of their potent activity in growth arrest, differentiation and apoptotic death of cancer cells. Pretreatment with valproic acid improved the propagation and therapeutic efficacy of oncolytic HSV in a human glioma xenograft model in vivo indicating that histone deacetylase inhibitors can improve the efficacy of tumor virotherapies. ${ }^{41}$ Valproic acid can also alter the expression of the Coxsackie-adenovirus receptor as it was shown in bladder cancer that exerts an antineoplastic effect by inhibiting invasion as well as tumor growth. ${ }^{42}$

\section{Oncolytic viruses as gene carriers}

To further increase the therapeutic effect of replicating viral vectors, oncolytic viruses have recently been used for high-efficiency transgene expression. The rationale is that the intratumoral propagation of replicative viruses would overcome the low levels of gene transfer achieved by conventional non-replicating viral vectors. Simultaneous delivery of exogenous p53 via Ad5CMV-p53, and Delta24 adenovirus in glioma cells resulted in an additive effect on cell death, which was independent of the p53 status of cells. These results indicated that Ad5CMV-p53 enhanced the oncolytic effect of the Delta-24 adenovirus. ${ }^{43}$ E1 transcomplementation of a replication-competent adenovirus-encoding p53 resulted in dramatic augmentation of cell killing and circumvented resistance to apoptosis obviating the potential utility of therapeutic transgene expression by a replicating adenovirus. ${ }^{44}$ Evaluation of AdDelta24-p53 in comparison with its parent Delta-24, showed better efficiency and caused more frequent regression of glioma xenografts. ${ }^{45}$ In vivo, combination therapy of radiotherapy with either Delta-24 or AdDelta24-p53 significantly increased the number of mice showing tumor regression $(100 \%)$ and long-term survival $(50 \%)$, but no differences between the two viruses were noted, suggesting that exogenous p53 expression did not increase the synergistic interaction of conditionally replicative adenoviruses with radiotherapy. ${ }^{46}$ Other modifications of the Delta-24, included addition of the herpes simplex virus type 1 thymidine kinase-green fluorescent protein fusion gene (TK-GFP) encompassing CRAd (Ad5Delta24TK-GFP), that could efficiently penetrate into tumors and cause oncolysis. ${ }^{47}$

An oncolytic herpes simplex virus that expressed human tissue inhibitor of metalloproteinases 3 or firefly luciferase showed enhanced antitumor efficacy through multiple mechanisms, including direct cytotoxicity, elevated virus titer and reduced tumor neovascularization. ${ }^{48}$ Systemic administration of a modified vaccinia virus carrying three transgenes encoding light-emitting proteins, induced regression of breast tumors in preclinical models and in addition it was possible to monitor the antitumor activity of the virus by optical imaging. ${ }^{49}$

\section{Oncolytic viruses and chemotherapy}

Adenoviruses express proteins that downregulate $\mathrm{O}(6)$ methylguanine-DNA methyltransferase, or degrade poly (ADP-ribose) polymerase and Mre11-Rad50-NBS1 complex, which detects DNA strand breaks. The combination of Delta-24-RGD and temozolomide induced a synergistic effect in glioma cells associated with downmodulation of the RNA levels of the DNA-repair enzyme O(6)methylguanine-DNA methyltransferase, that mediates resistance to temozolomide. ${ }^{50}$ Equally, the combination of Delta-24 with irinotecan (CPT-11) showed an enhanced anticancer effect, suggesting that Delta-24 could sensitize glioma cells to the topoisomerase I inhibitor irinotecan. $^{51}$ Delta-24-RGD, in combination with everolimus (RAD001), resulted in an enhanced antiglioma effect in vivo via autophagy and increased long-term survival of glioma-bearing animals. ${ }^{52}$

Combination of ICOVIR-5 with RAD001 or TMZ showed a potent antiglioma effect both in vitro and in vivo in athymic mice bearing glioma xenografts. ${ }^{53}$

Temozolomide enhanced herpes simplex virus oncolysis by upregulating the DNA-repair-related genes growth arrest DNA damage 34 and ribonucleotide reductase. The favorable interactions between viruses and the DNArepair machinery suggest that combining temozolomide with viral therapy may overcome the limitations of a single therapy by counteracting chemoresistance or improved viral oncolysis. ${ }^{54}$

A Delta-24 construct (Delta24-hyCD) expressing a humanized form of the saccharomyces cerevisiae cytosine deaminase gene (hyCD) administered intracranially with concomitant 5-fluorocytosine in animals with gliomas showed improved cytotoxicity and animal survival compared with Delta-24 alone. ${ }^{55}$ OBP-405, an oncolytic adenovirus regulated by the human telomerase reverse transcriptase promoter (hTERT-Ad, OBP-301) with a tropism modification (RGD) showed a strong antitumor effect on glioblastoma cells mediated by autophagy. Moreover, temozolomide and rapamycin administered in combination with OBP-405 in mice with intracranial gliomas resulted in prolonged survival. ${ }^{56}$

The adenovirus d1520, which lacks the E1A 13S protein, replicated efficiently and showed oncolytic potential in multidrug-resistant cells with nuclear localization of the human transcription factor YB-1. Combination of d1520 with the chemotherapeutic agent irinotecan, enhanced nuclear localization of YB-1 and cell death. Similar results were obtained with a combination of $\mathrm{d} 1520$ with the histone deacetylase inhibitor trichostatin A, by upregulating Coxsackie virus-adenovirus receptor expression. Interestingly, combining both agents, the replication efficiency and induction of cytopathic effect of dl520 were further augmented indicating that combining virotherapy, 
chemotherapy and histone deacetylase inhibitor treatment may be an approach to enhance the oncolytic efficacy of d1520 ${ }^{57}$ Moreover, combined $\mathrm{d} 1520$ and radiotherapy in glioma cell lines in vitro and in human tumor xenografts increased the oncolytic effect of d1520 with enhanced viral replication, viral yield and viral release and inhibited the growth of subcutaneous U373 tumors in a xenograft mouse model via increase of nuclear YB-1. ${ }^{58}$

In vitro studies have indicated that G207, a mutant oncolytic HSV, can target glioma cells ${ }^{59}$ especially those that survive temozolomide treatment. ${ }^{60}$ However, the oncolytic HSV G207 retained the ability of wild-type HSV to increase infected tissue vascularity, which is mediated by reduced thrombospondin-1 and thrombospondin-2 levels and causes delayed tumor growth resumption. The angiogenesis induced by HSV G207 could be counteracted by administering thrombospondin-derived peptides and should be considered when designing oncolytic HSV therapies. $^{61}$ Animal studies showed that pre-treatment with cyclophosphamide enhanced the oncolytic effect of an HSV and reduced HSV-mediated increase in CD68+ and CD163 + cells. $^{62}$ The gene product of HSV Us3 protects virus-infected cells from apoptosis, a cellular pathway frequently dysfunctional in tumors. Us3 deletion confers enhanced tumor selectivity of HSV-1 and because it also provokes Akt activation, it sensitizes cells to phosphatidylinositol 3-kinase-Akt inhibitors during combination therapy. ${ }^{63}$

\section{Clinical trials}

Several gene therapy clinical trials have been conducted using various vectors for gliomas (Table 2). In a phase I clinical trial, 11 patients with recurrent malignant glioma received escalating doses of Ad.hIFN- $\beta$ by stereotactic injection. One patient experienced dose-limiting treatment-related grade 4 confusion following the postoperative injection. At the highest doses tested, a reproducible increase in tumor cell apoptosis in posttreatment versus pre-treatment biopsies was observed. ${ }^{64}$ Another phase I clinical trial of patients with recurrent glioblastoma treated with adenovirus/herpex simplexthymidine kinase/ganciclovir (ADV/HSV-tk/GC) reported no adenoviral vector shedding, local or systemic toxicity and lack of increased brain edema in the treated patients. Ten of 11 treated patients survived $\geqslant 52$ weeks from initial diagnosis with an average survival of 112.3 weeks and one patient surviving over 248 weeks from diagnosis. ${ }^{65}$ In a phase I-II trial, both retroviruspackaging cells (PA317/tk) (eight tumors in seven patients) and adenoviruses (Adv/tk) (seven tumors in seven patients) were used for local gene therapy of recurrent malignant glioma. Seven patients received only surgery (controls). Four patients with adenovirus injections had a significant increase in antiadenovirus antibodies including two patients with a short-term fever reaction, and two patients had increased frequency of epileptic seizures, but no other significant adverse events. The mean survival of the control group was 8.3 months.
All gliomas treated with the retrovirus showed progression in 3 months (mean survival 7.4 months), but three of the seven patients treated with $\mathrm{Adv} / \mathrm{tk}$ remained stable (mean survival 15 months), suggesting that further trials were justified with adenovirus vectors. ${ }^{66}$ In a randomized, controlled study in 36 patients with primary or recurrent malignant glioma, 17 patients were randomized to receive AdvHSV-tk (Cerepro) gene therapy by local injection into the wound bed after tumor resection, followed by intravenous ganciclovir and 19 control patients received standard care with radical resection followed by radiotherapy in those patients with primary tumors. AdvHSVtk treatment produced a statistically significant increase in mean survival from 39 to 71 weeks. The treatment was well tolerated and the investigators concluded that AdvHSV-tk gene therapy with ganciclovir is a potential beneficial therapy for primary or recurrent high-grade glioma. ${ }^{67}$

In a phase III, multicenter, randomized, controlled trial in 248 patients with newly diagnosed previously untreated glioblastoma multiforme, patients received standard therapy (surgical resection and radiotherapy) or standard therapy plus adjuvant gene therapy during surgery. The gene therapy consisted of retroviral vector-producing cells carrying the HSV-tk gene cDNA followed by intravenous infusion of ganciclovir. Progression-free median survival in the gene therapy group was 180 days compared with 183 days in control subjects. Median survival was 365 versus 354 days, and 12-month survival rates were 50 versus $55 \%$ in the gene therapy and control groups, respectively. Thus, the gene therapy improved neither time to tumor progression nor overall survival time, although the feasibility and good biosafety profile of this gene therapy strategy were further supported. ${ }^{68}$ However, the failure of this specific protocol, as the authors suggested, may be due to the poor rate of delivery of the HSV-tk gene to tumor cells through the retroviral vector-producing cells. ${ }^{68}$ In a recent multicenter clinical trial in 236 patients with malignant gliomas, patients were randomized to receive either standard care (surgery and radiotherapy or surgery and radiotherapy followed by temozolomide chemotherapy), or standard therapy plus Cerepro (one administration by multiple injection into the healthy brain at the end of the tumor resection procedure). In the latest update analysis of this study, median survival and adverse event profile results are in agreement with those of previous studies, ${ }^{67}$ showing consistent improved overall survival in patients who received Cerepro compared with standard treatment (www.arktherapeutics.com). Thus, use of adenoviral vectors rather than retroviral vectors could enhance gene delivery to tumor tissues and result in therapeutic benefit.

Systemic administration of gene therapy was tried in a phase I/II trial, which included 11 recurrent glioblastoma patients that received repetitive intravenous administration of NDV-HUJ, the oncolytic HUJ strain of Newcastle disease virus. Toxicity was minimal with grade I/II constitutional fever seen in five patients. NDV-HUJ was recovered from blood, saliva and urine samples and 
Table 2 Representative gene therapy clinical trials for gliomas

\begin{tabular}{|c|c|c|c|c|}
\hline Clinical Trial & No & Methods & Toxicity & Results \\
\hline $\begin{array}{l}\text { Chiocca et al, } 2008^{64} \\
\text { Phase I }\end{array}$ & 11 & $\begin{array}{l}\text { Ad.hIFN- } \beta \text {, twice IC injection, escalating } \\
\text { dose }\end{array}$ & Grade IV confusion, one patient & Induction of apoptosis in parts of tumor \\
\hline Chiocca et al, $2004^{72}$ & 24 & ONYX-015, IC injection, escalating dose & NS & MTP, 46 days (13-452+days) \\
\hline Phase I & & & & $\begin{array}{l}\text { MST, } 6.2 \text { months (range } 1.3 \text { to } \\
28.0+\text { months) }\end{array}$ \\
\hline $\begin{array}{l}\text { Germano et al, } 2003^{65} \\
\text { Recurrent gliomas after surgery and XRT, } \\
\text { Phase I }\end{array}$ & 11 & $\begin{array}{l}\mathrm{ADV} / \mathrm{HSV}-\mathrm{tk} / \mathrm{GC} \mathrm{IC} \text { injection, after tumor } \\
\text { resection, escalating dose }\end{array}$ & NS & $\begin{array}{l}\text { Ten of } 11 \text { patients survived }>\text { or }=52 \\
\text { weeks from diagnosis }\end{array}$ \\
\hline $\begin{array}{l}\text { Sandmair et al, } 2000^{66} \\
\text { Recurrent gliomas after surgery and XRT, } \\
\text { Phase I-II }\end{array}$ & 21 & $\begin{array}{l}\text { Seven patients, RV/HSV-tk/GC; } 7 \\
\text { patients, ADV/HSV-tk/GC; seven } \\
\text { patients, control (only tumor resection) }\end{array}$ & $\begin{array}{l}\text { None with RV; four patients with ADV } \\
\text { had increased antibodies and two had } \\
\text { fever; two patients had increased in } \\
\text { seizure activity }\end{array}$ & $\begin{array}{l}\text { Mean survival: RV/HSV-tk/GC, } 7.4 \\
\text { months; ADV/HSV-tk/GC, } 15 \text { months; } \\
\text { Control, } 8.3 \text { months }\end{array}$ \\
\hline $\begin{array}{l}\text { Immonen et al, } 2004^{67} \text { Recurrent or untreated } \\
\text { gliomas after surgery and XRT, Phase III, } \\
\text { randomized }\end{array}$ & 36 & $\begin{array}{l}\text { 17, standard therapy (surgery+RT for } \\
\text { untreated gliomas) plus ADV/HSV-tk/ } \\
\text { GC; } 19 \text {, standard therapy }\end{array}$ & $\begin{array}{l}\text { Overall safe, adenoviral antibody titers } \\
\text { raised in six patients }\end{array}$ & $\begin{array}{l}\text { Mean survival: standard therapy, } 39 \\
\text { weeks; ADV/HSV-tk/GC, } 71 \text { weeks }\end{array}$ \\
\hline $\begin{array}{l}\text { Rainov et al, } 2000^{68} \text { phase III, randomized, } \\
\text { controlled trial, new untreated GBM }\end{array}$ & 248 & $\begin{array}{l}\text { Standard therapy (surgery and XRT) or } \\
\text { standard therapy plus IC RV HSV-tk }\end{array}$ & NS & $\begin{array}{l}\text { MTP } 183 \text { days versus } 180 \text { days } \\
\text { MST, } 365 \text { days versus } 354 \text { days }\end{array}$ \\
\hline $\begin{array}{l}\text { Freeman et al, } 2006^{69} \\
\text { Phase I/II, recurrent GBM }\end{array}$ & 11 & $\begin{array}{l}\text { NDV-HUJ, the oncolytic strain of } \\
\text { Newcastle disease virus, repetitive IV } \\
\text { administration, escalating dose }\end{array}$ & $\begin{array}{l}\text { Grade } \mathrm{I} / \mathrm{Il} \text { constitutional fever in } 5 \\
\text { patients) } \\
\text { NDV-HUJ was recovered from body } \\
\text { fluids and one tumor biopsy }\end{array}$ & One patient had a complete response \\
\hline $\begin{array}{l}\text { Lang et al, } 2003^{70} \text { Recurrent gliomas after } \\
\text { surgery and XRT, Phase I }\end{array}$ & 12 & $\begin{array}{l}\text { Ad-p53 injected IC and repeated after } \\
\text { tumor resection }\end{array}$ & $\begin{array}{l}\text { Clinical toxicity was minimal, anti- } \\
\text { adenovirus type } 5 \text { titers increased in } \\
\text { most patients }\end{array}$ & $\begin{array}{l}\text { transfected cells resided on average } \\
\text { within } 5 \mathrm{~mm} \text { of the injection site }\end{array}$ \\
\hline $\begin{array}{l}\text { Forsyth et al, } 2008^{71} \\
\text { Recurrent GBM, Phase I/II }\end{array}$ & 12 & $\begin{array}{l}\text { Oncolytic reovirus, IC administration, } \\
\text { escalating dose }\end{array}$ & Minimal toxicity, No grade III or IV & $\begin{array}{l}10 \text { patients had progression, } 1 \text { stable, } 1 \\
\text { not evaluable Median TTP was } 4.3 \\
\text { weeks (range, 2.6-39) } \\
\text { MST, } 21 \text { weeks (range, } 6-234 \text { ) }\end{array}$ \\
\hline
\end{tabular}

IC, intracranial; GBM, glioblastoma multiforme; TTP, time to progression; MST, median survival time; XRT, radiation therapy; RV, retrovirus; Ad, adenovirus; HSV, herpes simplex virus; TK, thymidine kinase; GC, gancyclovir; NS, not significant. 
one tumor biopsy. One patient achieved a complete response, suggesting need for further evaluation. ${ }^{69}$

Intracranial administration of exogenous p53 gene therapy using an adenovirus vector (Ad-p53, INGN 201), in a phase I clinical trial of 15 recurrent glioblastoma patients showed that the transfected cells resided within $5 \mathrm{~mm}$ of the injection site and there was no evidence of systemic viral dissemination. Thus, although toxicity was minimal, the finding that transduced cells were located only within a short distance of the injection site renders this specific therapeutic approach ineffective. ${ }^{70}$ Similarly, intratumoral administration of an oncolytic reovirus in a phase I trial in 12 patients with malignant gliomas at third recurrence showed no grade III or IV adverse events, and no therapeutic activity because 10 patients had tumor progression, one had stabilization, and one was not evaluable for response. Median TTP was 4.3 weeks. $^{71}$ In a dose-escalation trial of intracerebral injections of ONYX-015 after tumor resection in 24 patients, no serious adverse events related to treatment were noted. The median time to progression was 46 days. One patient had stable disease and one patient showed regression of interval-increased enhancement, but all the other patients had progression. ${ }^{72}$

\section{Stem cells}

Gene delivery by embryonic stem cells for malignant glioma therapy is currently under intense research. ${ }^{73}$ Stem cell therapy represents a promising therapeutic modality for cancer, based on their potent migratory tropism for malignant cells (Table 1). It is likely that tumorupregulated VEGF and angiogenic-activated microvasculature may be factors that mediate guidance signals for mesenchymal stem cells (MSC) tropism toward brain tumors. $^{74}$ There is evidence that active tumor sites attract exogenous MSCs rendering them attractive as delivery vehicles for various anticancer factors, including cytokines, pro-drugs and replicative adenovirus. ${ }^{75}$ MSCs can be derived from bone marrow and they consist of multi-potent stem cells that are capable of differentiating into both mesenchymal and non-mesenchymal lineages. Recent evidence points to the existence of stem cell stores in adult tissues, in addition to the well-known hematopoietic stem cells from bone marrow. Lipoaspirates and dermis represent accessible sources for obtaining stem cells, with minimal discomfort to the donor, and might be promising candidates for cell-therapy procedures once their features are experimentally accessed. ${ }^{76}$

Transfer of the gene for interleukin-4 into C57BL6J mouse primary neural progenitor cells and injection into established syngeneic brain glioblastomas led to the survival of most tumor-bearing mice. This gene therapy approach was based on the grafting of neural stem cells (NSC) producing therapeutic molecules. ${ }^{77}$ Well-characterized NSC lines (lacZ and/or CD-positive) injected into the tail vein of adult nude mice with established experimental intracranial and/or subcutaneous flank tumors of neural and non-neural origin were localized to various tumor sites with little accumulation in normal tissues. These findings suggested that intravascularly administered NSCs may be an effective delivery vehicle to target invasive tumors of neural and non-neural origin, both within and outside the brain. ${ }^{78}$

In general, systemic adenoviral delivery into tumors is inefficient because of liver sequestration of intravenously administered virus. Delivery of a CRAd by human MSCs was 46-fold more efficient than injection of CRAd alone indicating that human MSC migrate and deliver CRAd to distant glioma cells. ${ }^{79}$ In addition, NSCs mediated an enhanced intratumoral distribution of a CRAd in malignant glioma when compared with virus injection alone. ${ }^{80}$ However, another study showed that adenoviral infection of adipose-derived stem cells, which display the same tropism for gliomas as NSCs, resulted in poor in vivo migration, most likely because of an inflammatory response to these cells, which was not observed with control non-infected adipose-derived stem cells. These results indicated that although adipose-derived stem cells are an interesting candidate for further development of the cell-based therapy of gliomas, adenoviruses are not appropriate vectors for delivery of transgenes with adipose-derived stem cells. ${ }^{81}$

Neural stem cells transduced with herpes simplex virusthymidine kinase gene (NSC-tk) that were intracranially implanted in bilateral hemispheres of a C6 rat glioma model, migrated towards C6 cells even when they were implanted in the contralateral hemisphere. When gancyclovir was systemically administered, growth of intracranial tumor was markedly inhibited and the survival was significantly prolonged suggesting that NSC-tk therapy may be suitable for treatment of malignant gliomas that infiltrate and widely disseminate in the brain. ${ }^{82}$ Similar results were noted in 9-1 glioma-bearing rats after injection of MSCs. In addition, gene-modification of MSCs by infection with an adenoviral vectorencoding human interleukin-2 enhanced the antitumor effect and further prolonged survival. ${ }^{83}$

Combination of suppression of miR-21 via locked nucleic acid (LNA)-antimiR-21 oligonucleotides and NSCs expressing a secretable variant of the cytotoxic agent tumor necrosis factor-related apoptosis-inducing ligand (S-TRAIL), led to a synergistic increase in caspase activity and decreased cell viability in human glioma cells in vitro and in vivo. ${ }^{84}$ Although TRAIL selectively kills tumor cells, its short half-life, poor delivery and TRAIL-resistant tumor cells have diminished its clinical efficacy. Delivery of TRAIL through an adeno-associated virus vector or via stem cells led to a cell-killing effect in multiple glioma lines. Addition of temozolomide which induced accumulation of cells in $G(2)-M$ phase and increased TRAIL receptor expression, enhanced cell killing and markedly upregulated proapoptotic proteins in glioma cells. ${ }^{85}$ Human umbilical cord blood-derived mesenchymal stem cells carrying a secretable trimeric form of TRAIL injected into the tumor mass or the opposite hemisphere of established human glioma in nude mice, showed that MSC-based secretable trimeric form of 
TRAIL gene delivery had better therapeutic efficacy compared with direct injection of adenovirus encoding the secretable trimeric form of TRAIL gene into the glioma. ${ }^{86}$

However, potential detrimental side effects of stem cells must be resolved before their consideration for treatment of human glioma and other cancers. An important issue that needs to be addressed is their safety and to rule out the potential of their neoplastic transformation. Recent research suggested that normal adult glial progenitor cells have the capacity to give rise to gliomas, not only when they express a mitogenic protein but also when they are in the vicinity of other tumor stem cells secreting the mitogenic agent, thus contributing significantly to the heterogeneous mass of cells that compose a malignant glioma. ${ }^{87}$

\section{Concluding remarks}

Replication-deficient viruses as gene carriers have revolutionized the study of glioma biology since have attained sufficient gene expression in vitro and in laboratory animals. The relative poor therapeutic effect though led to the development of replication-competent viruses which can be used both as gene delivery vehicles to tumors and in addition independently induce oncolysis and avoid damage of the adjacent normal cells. Similar approach consists of the use of stem cells for more efficient delivery of genetic material to glioma cells. However, since the introduction of these technologies several important technical and safety issues are needed to be resolved before we can see any significant advantage over the standard therapies for gliomas in the clinic. Nevertheless, continuing research in improvement of gene transfer efficiency and stem cell technology may overcome these limitations, and these new therapies may have a significant role in the management of gliomas in the future.

\section{Conflict of interest}

The authors declare no conflict of interest.

\section{Acknowledgements}

We thank the pharmaceutical company Genesis, Greece, for their financial assistance for reproduction of the color figures and page charges. This research was supported by National Cancer Institute grants CA 75557, CA 92393, CA 95058, and CA 116708 (to JSR).

\section{References}

1 Kyritsis A. Evaluation and treatment of CNS neoplasms K1998. In: Lechtenberg R, Schutta HS (eds). Neurology Practice Guidelines. Marcel Dekker: New York, 1998 pp 473-496.
2 Kyritsis AP. Chemotherapy for malignant gliomas K1993. Oncology (Williston Park) 1993; 7: 93-100.

3 Levin VA, Giglio P, Kyritsis AP. The management of gliomas, medulloblastoma, CNS germ cell tumors, and carcinomas metastatic to the CNS L2005. In: Cavalli F, Hansen H, Kaye S (eds). Textbook of Medical Onco$\log y$. second ed. Martin Dunitz: London, England, 2005 pp 415-430.

4 Fueyo J, Gomez-Manzano C, Yung WK, Kyritsis AP. Targeting in gene therapy for gliomas. Arch Neurol 1999; 56: 445-448.

5 Fueyo J, Gomez-Manzano C, Yung WK, Kyritsis AP. The functional role of tumor suppressor genes in gliomas: clues for future therapeutic strategies. Neurology 1998; 51: $1250-1255$.

6 Fueyo J, Gomez-Manzano C, Yung WK, Liu TJ, Alemany $\mathrm{R}, \mathrm{McDonnell} \mathrm{TJ}$ et al. Overexpression of E2F-1 in glioma triggers apoptosis and suppresses tumor growth in vitro and in vivo. Nat Med 1998; 4: 685-690.

7 Mulligan RC. The basic science of gene therapy. Science 1993; 260: 926-932.

8 Hunt KK, Vorburger SA. Tech sight. Gene therapy. Hurdles and hopes for cancer treatment. Science 2002; 297: 415-416.

9 Donsante A, Miller DG, Li Y, Vogler C, Brunt EM, Russell DW et al. AAV vector integration sites in mouse hepatocellular carcinoma. Science 2007; 317: 477.

10 Goussia AC, Agnantis NJ, Rao JS, Kyritsis AP. Cytogenetic and molecular abnormalities in astrocytic gliomas (Review) G2000A. Oncol Rep 2000; 7: 401-412.

11 Hama S, Matsuura S, Tauchi H, Yamasaki F, Kajiwara Y, Arita $\mathrm{K}$ et al. p16 gene transfer increases cell killing with abnormal nucleation after ionising radiation in glioma cells. Br J Cancer 2003; 89: 1802-1811.

12 Chintala SK, Fueyo J, Gomez-Manzano C, Venkaiah B, Bjerkvig R, Yung WK et al. Adenovirus-mediated p16/ CDKN2 gene transfer suppresses glioma invasion in vitro. Oncogene 1997; 15: 2049-2057.

13 Adachi Y, Lakka SS, Chandrasekar N, Yanamandra N, Gondi CS, Mohanam S et al. Down-regulation of integrin alpha(v)beta(3) expression and integrin-mediated signaling in glioma cells by adenovirus-mediated transfer of antisense urokinase-type plasminogen activator receptor (uPAR) and sense p16 genes. J Biol Chem 2001; 276: 47171-47177.

14 Adachi Y, Chandrasekar N, Kin Y, Lakka SS, Mohanam S, Yanamandra $\mathrm{N}$ et al. Suppression of glioma invasion and growth by adenovirus-mediated delivery of a bicistronic construct containing antisense uPAR and sense p16 gene sequences. Oncogene 2002; 21: 87-95.

15 Hama S, Heike Y, Naruse I, Takahashi M, Yoshioka H, Arita $\mathrm{K}$ et al. Adenovirus-mediated p16 gene transfer prevents drug-induced cell death through G1 arrest in human glioma cells. Int $J$ Cancer 1998; 77: 47-54.

16 Fueyo J, Gomez-Manzano C, Puduvalli VK, Martin-Duque $\mathrm{P}$, Perez-Soler R, Levin VA et al. Adenovirus-mediated p16 transfer to glioma cells induces G1 arrest and protects from paclitaxel and topotecan: implications for therapy. Int $J$ Oncol 1998; 12: 665-669.

17 Gomez-Manzano C, Fueyo J, Kyritsis AP, McDonnell TJ, Steck PA, Levin VA et al. Characterization of p53 and p21 functional interactions in glioma cells en route to apoptosis. J Natl Cancer Inst 1997; 89: 1036-1044.

18 Paul CP, Everts M, Glasgow JN, Dent P, Fisher PB, Ulasov IV et al. Characterization of infectivity of knobmodified adenoviral vectors in glioma. Cancer Biol Ther 2008; 7: 786-793. 
19 Wohlfahrt ME, Beard BC, Lieber A, Kiem HP. A capsidmodified, conditionally replicating oncolytic adenovirus vector expressing TRAIL Leads to enhanced cancer cell killing in human glioblastoma models. Cancer Res 2007; 67: 8783-8790.

20 Szentirmai O, Baker CH, Bullain SS, Lin N, Takahashi M, Folkman $\mathbf{J}$ et al. Successful inhibition of intracranial human glioblastoma multiforme xenograft growth via systemic adenoviral delivery of soluble endostatin and soluble vascular endothelial growth factor receptor-2: laboratory investigation. $J$ Neurosurg 2008; 108: 979-988.

21 King GD, Muhammad AK, Xiong W, Kroeger KM, Puntel M, Larocque D et al. High-capacity adenovirus vector-mediated anti-glioma gene therapy in the presence of systemic antiadenovirus immunity. J Virol 2008; 82: 4680-4684.

22 Fueyo J, Gomez-Manzano C, Yung WK, Kyritsis AP. Targeting in gene therapy for gliomas F1999. Arch Neurol 1999; 56: 445-448.

23 Brouwer E, Havenga MJ, Ophorst O, de LB, Gijsbers L, Gillissen $\mathrm{G}$ et al. Human adenovirus type 35 vector for gene therapy of brain cancer: improved transduction and bypass of pre-existing anti-vector immunity in cancer patients. Cancer Gene Ther 2007; 14: 211-219.

24 Van Houdt WJ, Wu H, Glasgow JN, Lamfers ML, Dirven CM, Gillespie GY et al. Gene delivery into malignant glioma by infectivity-enhanced adenovirus: in vivo versus in vitro models. Neuro Oncol 2007; 9: 280-290.

25 Kargiotis O, Chetty C, Gondi CS, Tsung AJ, Dinh DH, Gujrati $\mathrm{M}$ et al. Adenovirus-mediated transfer of siRNA against MMP-2 mRNA results in impaired invasion and tumor-induced angiogenesis, induces apoptosis in vitro and inhibits tumor growth in vivo in glioblastoma. Oncogene 2008; 27: 4830-4840.

26 Fueyo J, Gomez-Manzano C, Yung WK, Liu TJ, Alemany $\mathrm{R}$, Bruner JM et al. Suppression of human glioma growth by adenovirus-mediated Rb gene transfer. Neurology 1998; 50: 1307-1315.

27 Benitez JA, Arregui L, Vergara P, Segovia J. Targetedsimultaneous expression of Gas1 and p53 using a bicistronic adenoviral vector in gliomas. Cancer Gene Ther 2007; 14: 836-846.

28 Andreansky S, Soroceanu L, Flotte ER, Chou J, Markert JM, Gillespie GY et al. Evaluation of genetically engineered herpes simplex viruses as oncolytic agents for human malignant brain tumors. Cancer Res 1997; 57: $1502-1509$.

29 Niranjan A, Wolfe D, Tamura M, Soares MK, Krisky DM, Lunsford LD et al. Treatment of rat gliosarcoma brain tumors by HSV-based multigene therapy combined with radiosurgery. Mol Ther 2003; 8: 530-542.

30 Ries SJ. Elucidation of the molecular mechanism underlying tumor-selective replication of the oncolytic adenovirus mutant ONYX-015. Future Oncol 2005; 1: 763-766.

31 Fueyo J, Gomez-Manzano C, Alemany R, Lee PS, McDonnell TJ, Mitlianga $\mathrm{P}$ et al. A mutant oncolytic adenovirus targeting the $\mathrm{Rb}$ pathway produces anti-glioma effect in vivo. Oncogene 2000; 19: 2-12.

32 Jiang H, Gomez-Manzano C, Alemany R, Medrano D, Alonso M, Bekele BN et al. Comparative effect of oncolytic adenoviruses with E1A-55 kDa or E1B-55 kDa deletions in malignant gliomas. Neoplasia 2005; 7: 48-56.

33 Fueyo J, Alemany R, Gomez-Manzano C, Fuller GN, Khan A, Conrad CA et al. Preclinical characterization of the antiglioma activity of a tropism-enhanced adenovirus targeted to the retinoblastoma pathway. $J$ Natl Cancer Inst 2003; 95: 652-660.

34 Jiang H, Gomez-Manzano C, Aoki H, Alonso MM, Kondo $\mathrm{S}$, McCormick $\mathrm{F}$ et al. Examination of the therapeutic potential of Delta-24-RGD in brain tumor stem cells: role of autophagic cell death. J Natl Cancer Inst 2007; 99: $1410-1414$.

35 Alonso MM, Cascallo M, Gomez-Manzano C, Jiang H, Bekele BN, Perez-Gimenez A et al. ICOVIR-5 shows E2F1 addiction and potent antiglioma effect in vivo. Cancer Res 2007; 67: 8255-8263.

36 Brouwer E, Havenga MJ, Ophorst O, de LB, Gijsbers L, Gillissen $\mathrm{G}$ et al. Human adenovirus type 35 vector for gene therapy of brain cancer: improved transduction and bypass of pre-existing anti-vector immunity in cancer patients. Cancer Gene Ther 2007; 14: 211-219.

37 Gomez-Manzano C, Balague C, Alemany R, Lemoine MG, Mitlianga $\mathrm{P}$, Jiang $\mathrm{H}$ et al. A novel E1A-E1B mutant adenovirus induces glioma regression in vivo. Oncogene 2004; 23: $1821-1828$

38 Chou J, Roizman B. The gamma 1(34.5) gene of herpes simplex virus 1 precludes neuroblastoma cells from triggering total shutoff of protein synthesis characteristic of programed cell death in neuronal cells C1992. Proc Natl Acad Sci USA 1992; 89: 3266-3270.

39 Goldstein DJ, Weller SK. Factor(s) present in herpes simplex virus type 1-infected cells can compensate for the loss of the large subunit of the viral ribonucleotide reductase: characterization of an ICP6 deletion mutant G1988. Virology 1988; 166: 41-51.

40 Aghi M, Visted T, Depinho RA, Chiocca EA. Oncolytic herpes virus with defective ICP6 specifically replicates in quiescent cells with homozygous genetic mutations in $\mathrm{p} 16$. Oncogene 2008; 27: 4249-4254.

41 Otsuki A, Patel A, Kasai K, Suzuki M, Kurozumi K, Chiocca EA et al. Histone deacetylase inhibitors augment antitumor efficacy of herpes-based oncolytic viruses. Mol Ther 2008; 16: 1546-1555.

42 Chen CL, Sung J, Cohen M, Chowdhury WH, Sachs MD, Li $\mathrm{Y}$ et al. Valproic acid inhibits invasiveness in bladder cancer but not in prostate cancer cells C2006. J Pharmacol Exp Ther 2006; 319: 533-542.

43 Mitlianga PG, Sioka C, Vartholomatos G, Goussia A, Polyzoidis K, Rao JS et al. p53 enhances the Delta-24 conditionally replicative adenovirus anti-glioma effect. Oncol Rep 2006; 15: 149-153.

44 Haviv YS, Takayama K, Glasgow JN, Blackwell JL, Wang $\mathrm{M}$, Lei X et al. A model system for the design of armed replicating adenoviruses using p53 as a candidate transgene. Mol Cancer Ther 2002; 1: 321-328.

45 Geoerger B, Vassal G, Opolon P, Dirven CM, Morizet J, Laudani $\mathrm{L}$ et al. Oncolytic activity of p53-expressing conditionally replicative adenovirus AdDelta24-p53 against human malignant glioma. Cancer Res 2004; 64: $5753-5759$.

46 Idema S, Lamfers ML, van BV, Noske DP, Heukelom S, Moeniralm S et al. AdDelta24 and the p53-expressing variant AdDelta24-p53 achieve potent anti-tumor activity in glioma when combined with radiotherapy. J Gene Med 2007; 9: 1046-1056.

47 Hakkarainen T, Hemminki A, Curiel DT, Wahlfors J. A conditionally replicative adenovirus that codes for a TKGFP fusion protein (Ad5Delta24TK-GFP) for evaluation of the potency of oncolytic virotherapy combined with molecular chemotherapy. Int J Mol Med 2006; 18: 751-759. 
48 Mahller YY, Vaikunth SS, Ripberger MC, Baird WH, Saeki Y, Cancelas JA et al. Tissue inhibitor of metalloproteinase-3 via oncolytic herpesvirus inhibits tumor growth and vascular progenitors. Cancer Res 2008; 68: 1170-1179.

49 Zhang Q, Yu YA, Wang E, Chen N, Danner RL, Munson PJ et al. Eradication of solid human breast tumors in nude mice with an intravenously injected light-emitting oncolytic vaccinia virus. Cancer Res 2007; 67: 10038-10046.

50 Alonso MM, Gomez-Manzano C, Bekele BN, Yung WK, Fueyo J. Adenovirus-based strategies overcome temozolomide resistance by silencing the O6-methylguanineDNA methyltransferase promoter. Cancer Res 2007; 67: 11499-11504.

51 Gomez-Manzano C, Alonso MM, Yung WK, McCormick F, Curiel DT, Lang FF et al. Delta-24 increases the expression and activity of topoisomerase I and enhances the antiglioma effect of irinotecan. Clin Cancer Res 2006; 12: 556-562.

52 Alonso MM, Jiang H, Yokoyama T, Xu J, Bekele NB, Lang FF et al. Delta-24-RGD in combination with RAD001 induces enhanced anti-glioma effect via autophagic cell death. Mol Ther 2008; 16: 487-493.

53 Alonso MM, Gomez-Manzano C, Jiang H, Bekele NB, Piao $\mathrm{Y}$, Yung WK et al. Combination of the oncolytic adenovirus ICOVIR-5 with chemotherapy provides enhanced antiglioma effect in vivo. Cancer Gene Ther 2007; 14: 756-761.

54 Jiang H, Alonso MM, Gomez-Manzano C, Piao Y, Fueyo J. Oncolytic viruses and DNA-repair machinery: overcoming chemoresistance of gliomas. Expert Rev Anticancer Ther 2006; 6: 1585-1592.

55 Conrad C, Miller CR, Ji Y, Gomez-Manzano C, Bharara S, McMurray JS et al. Delta24-hyCD adenovirus suppresses glioma growth in vivo by combining oncolysis and chemosensitization. Cancer Gene Ther 2005; 12: 284-294.

56 Yokoyama T, Iwado E, Kondo Y, Aoki H, Hayashi Y, Georgescu MM et al. Autophagy-inducing agents augment the antitumor effect of telerase-selve oncolytic adenovirus OBP-405 on glioblastoma cells. Gene Therapy 2008; 15: 1233-1239.

57 Bieler A, Mantwill K, Dravits T, Bernshausen A, Glockzin $\mathrm{G}$, Kohler-Vargas $\mathrm{N}$ et al. Novel three-pronged strategy to enhance cancer cell killing in glioblastoma cell lines: histone deacetylase inhibitor, chemotherapy, and oncolytic adenovirus d1520. Hum Gene Ther 2006; 17: 55-70.

58 Bieler A, Mantwill K, Holzmuller R, Jurchott K, Kaszubiak A, Stark $\mathrm{S}$ et al. Impact of radiation therapy on the oncolytic adenovirus d1520: implications on the treatment of glioblastoma. Radiother Oncol 2008; 86: 419-427.

59 Huszthy PC, Goplen D, Thorsen F, Immervoll H, Wang J, Gutermann A et al. Oncolytic herpes simplex virus type-1 therapy in a highly infiltrative animal model of human glioblastoma. Clin Cancer Res 2008; 14: 1571-1580.

60 Aghi M, Rabkin S, Martuza RL. Effect of chemotherapyinduced DNA repair on oncolytic herpes simplex viral replication. J Natl Cancer Inst 2006; 98: 38-50.

61 Aghi M, Rabkin SD, Martuza RL. Angiogenic response caused by oncolytic herpes simplex virus-induced reduced thrombospondin expression can be prevented by specific viral mutations or by administering a thrombospondinderived peptide. Cancer Res 2007; 67: 440-444.

62 Fulci G, Breymann L, Gianni D, Kurozomi K, Rhee SS, Yu $\mathrm{J}$ et al. Cyclophosphamide enhances glioma virotherapy by inhibiting innate immune responses. Proc Natl Acad Sci USA 2006; 103: 12873-12878.

63 Liu TC, Wakimoto H, Martuza RL, Rabkin SD. Herpes simplex virus Us3(-) mutant as oncolytic strategy and synergizes with phosphatidylinositol 3-kinase-Akt targeting molecular therapeutics L2007. Clin Cancer Res 2007; 13 5897-5902.

64 Chiocca EA, Smith KM, McKinney B, Palmer CA, Rosenfeld S, Lillehei K et al. A phase I trial of Ad.hIFNbeta gene therapy for glioma. Mol Ther 2008; 16: 618-626.

65 Germano IM, Fable J, Gultekin SH, Silvers A. Adenovirus/ herpes simplex-thymidine kinase/ganciclovir complex: preliminary results of a phase I trial in patients with recurrent malignant gliomas. J Neurooncol 2003; 65: 279-289.

66 Sandmair AM, Loimas S, Puranen P, Immonen A, Kossila M, Puranen M et al. Thymidine kinase gene therapy for human malignant glioma, using replication-deficient retroviruses or adenoviruses. Hum Gene Ther 2000; 11: 2197-2205.

67 Immonen A, Vapalahti M, Tyynela K, Hurskainen H, Sandmair A, Vanninen R et al. AdvHSV-tk gene therapy with intravenous ganciclovir improves survival in human malignant glioma: a randomised, controlled study. Mol Ther 2004; 10: 967-972.

68 Rainov NG. A phase III clinical evaluation of herpes simplex virus type 1 thymidine kinase and ganciclovir gene therapy as an adjuvant to surgical resection and radiation in adults with previously untreated glioblastoma multiforme. Hum Gene Ther 2000; 11: 2389-2401.

69 Freeman AI, Zakay-Rones Z, Gomori JM, Linetsky E, Rasooly L, Greenbaum E et al. Phase I/II trial of intravenous NDV-HUJ oncolytic virus in recurrent glioblastoma multiforme. Mol Ther 2006; 13: 221-228

70 Lang FF, Bruner JM, Fuller GN, Aldape K, Prados MD, Chang $\mathrm{S}$ et al. Phase I trial of adenovirus-mediated p53 gene therapy for recurrent glioma: biological and clinical results. $J$ Clin Oncol 2003; 21: 2508-2518.

71 Forsyth P, Roldan G, George D, Wallace C, Palmer CA, Morris D et al. A phase I trial of intratumoral administration of reovirus in patients with histologically confirmed recurrent malignant gliomas. Mol Ther 2008; 16: 627-632.

72 Chiocca EA, Abbed KM, Tatter S, Louis DN, Hochberg FH, Barker F et al. A phase I open-label, dose-escalation, multi-institutional trial of injection with an E1B-attenuated adenovirus, ONYX-015, into the peritumoral region of recurrent malignant gliomas, in the adjuvant setting. Mol Ther 2004; 10: 958-966.

73 Germano IM, Uzzaman M, Keller G. Gene delivery by embryonic stem cells for malignant glioma therapy: hype or hope? G2008. Cancer Biol Ther 2008; 7: 1341-1347.

74 Schmidt NO, Przylecki W, Yang W, Ziu M, Teng Y, Kim SU et al. Brain tumor tropism of transplanted human neural stem cells is induced by vascular endothelial growth factor. Neoplasia 2005; 7: 623-629.

75 Fritz V, Jorgensen C. Mesenchymal stem cells: an emerging tool for cancer targeting and therapy. Curr Stem Cell Res Ther 2008; 3: 32-42.

76 Freitas CS, Dalmau SR. Multiple sources of non-embryonic multipotent stem cells: processed lipoaspirates and dermis as promising alternatives to bone-marrow-derived cell therapies. Cell Tissue Res 2006; 325: 403-411.

77 Benedetti S, Pirola B, Pollo B, Magrassi L, Bruzzone MG, Rigamonti D et al. Gene therapy of experimental brain tumors using neural progenitor cells. Nat Med 2000; 6: $447-450$.

78 Brown AB, Yang W, Schmidt NO, Carroll R, Leishear KK, Rainov NG et al. Intravascular delivery of neural stem cell lines to target intracranial and extracranial tumors of neural and non-neural origin. Hum Gene Ther 2003; 14: 1777-1785. 
79 Sonabend AM, Ulasov IV, Tyler MA, Rivera AA, Mathis JM, Lesniak MS. Mesenchymal stem cells effectively deliver an oncolytic adenovirus to intracranial glioma. Stem Cells 2008; 26: 831-841.

80 Tyler MA, Ulasov IV, Sonabend AM, Nandi S, Han Y, Marler S et al. Neural stem cells target intracranial glioma to deliver an oncolytic adenovirus in vivo. Gene Therapy 2009; 16: $262-278$

81 Lamfers M, Idema S, van MF, Schouten T, van d V, Vandertop $\mathrm{P}$ et al. Homing properties of adipose-derived stem cells to intracerebral glioma and the effects of adenovirus infection L2009. Cancer Lett 2009; 274: $78-87$.

82 Li S, Gao Y, Tokuyama T, Yamamoto J, Yokota N, Yamamoto $\mathrm{S}$ et al. Genetically engineered neural stem cells migrate and suppress glioma cell growth at distant intracranial sites. Cancer Lett 2007; 251: 220-227.

83 Nakamura K, Ito Y, Kawano Y, Kurozumi K, Kobune M, Tsuda $\mathrm{H}$ et al. Antitumor effect of genetically engineered mesenchymal stem cells in a rat glioma model. Gene Therapy 2004; 11: 1155-1164.

84 Corsten MF, Miranda R, Kasmieh R, Krichevsky AM, Weissleder R, Shah K. MicroRNA-21 knockdown disrupts glioma growth in vivo and displays synergistic cytotoxicity with neural precursor cell delivered S-TRAIL in human gliomas. Cancer Res 2007; 67: 8994-9000.

85 Hingtgen S, Ren X, Terwilliger E, Classon M, Weissleder R, Shah K. Targeting multiple pathways in gliomas with stem cell and viral delivered S-TRAIL and Temozolomide. Mol Cancer Ther 2008; 7: 3575-3585.

86 Kim SM, Lim JY, Park SI, Jeong CH, Oh JH, Jeong M et al. Gene therapy using TRAIL-secreting human umbilical cord blood-derived mesenchymal stem cells against intracranial glioma K2008. Cancer Res 2008; 68: 9614-9623.

87 Assanah M, Lochhead R, Ogden A, Bruce J, Goldman J, Canoll P. Glial progenitors in adult white matter are driven to form malignant gliomas by platelet-derived growth factorexpressing retroviruses. $J$ Neurosci 2006; 26: 6781-6790. 